10 - ORIGINAL ARTICLE

TECHNICAL SKILL

\title{
Translational microsurgery. A new platform for transplantation research ${ }^{1}$
}

\author{
Eiji Kobayashi', Junko Haga"I
}

DOI: http://dx.doi.org/10.1590/S0102-865020160030000010

IPhD, Professor, Department of Organ Fabrication, Keio University School of Medicine, Tokyo, Japan. Conception and design of the study, manuscript writing.

IIPhD, Department of Organ Fabrication, Keio University School of Medicine, Tokyo, Japan. Analysis of data, manuscript writing.

\footnotetext{
ABSTRACT

PURPOSE: Clinical microsurgery has been introduced in many fields, while experimental microsurgery has the cross-disciplinary features of the sciences and techniques for growth of medicine, pharmacology, veterinary, engineering etc. Training protocol, proposing a new name as Translational Microsurgery, was introduced.

METHODS: Reconstructive skills of hepatic artery in pediatric living donor liver transplantation were summarized. Ex vivo training protocol using artificial blood vessel for surgeons was proposed.

RESULTS: Clinical microsurgery requires anastomosis with delicate arteries and limited field of view. Our training protocol revealed that the relation between the score and speed was seen, while not all the surgeons with enough experience got high score. This training led to muster clinical skills and to apply excellent experimental works.

CONCLUSIONS: Our microsurgical training protocol has been planned from the points of clinical setting. Training for vascular anastomosis led to rodent transplantation models. These models were used for immunology and immunosuppressant research. Microsurgical techniques led to master catheter technique and to inject various drugs or gene vectors.

Key words: Liver Transplantation. Microsurgery. Rats.
} 


\section{Introduction}

Clinical microsurgery is a technique for working on microscopic areas under a stereomicroscope or loupe. Microsurgery is used widely in many surgical fields such as brain surgery, vascular surgery, plastic surgery, and reconstructive surgery ${ }^{1}$. To overcome the limited field of view and to master delicate or difficult procedures, non-living materials and animal models are useful. It is worth while saying that microsurgical techniques necessary to perform procedures in humans are same as that in mice or rats.

Many rat organ transplantation models had been developed, and the International Society for Experimental Microsurgery (ISEM) was established in 1991 by Sun Lee, who had disseminated experimental microsurgical technique ${ }^{2,3}$. The goal of this society is to disseminate research on experimental microsurgery around the world, and the society is characterized by its extremely varied cross-section across fields such as medicine, pharmacology, and veterinary medicine.

Translational research which promotes the research from experimental results to clinical application has been introduced a new area $^{4-6}$. I propose a new concept of Translational Microsurgery for research in microsurgical techniques. In this review, I reconsider the cross-disciplinary features of the sciences and skills, describe the usefulness of experimental microsurgery in various fields, and finally expand on my personal view to further growth of Surgical Research.

Translational technique training from the view point of clinical transplantation

Experimental producers were conducted according to the guidelines of the Animal Care Committee of Keio University.

Translational research has a key concept of two ways; from bench to bedside and feedback of clinical results to basic research ${ }^{4}$. Microsurgery has also two-way of both experimental and clinic. There are many training protocols from the different clinical backgrounds ${ }^{7,8}$. The author (E. K.) has been teaching the microsurgical technique for hepatic artery reconstruction in pediatric living donor liver transplantations performed at the Jichi Medical University Hospital ${ }^{9}$. In microsurgery in living donor liver transplantations, anastomosis is performed in a severely limited field of view and has difficulty as in brain surgery. In addition, since the anastomosed areas move as the patient breathes, it is sometimes necessary to have the anesthesiologist control the breathing in unaccustomed intervals. The anastomosis method used by the author is shown in Figure 1. In general, if using an assistant when suturing, first suture the top and bottom of both ends with a knotted suture, then have the assistant hold both ends and twist 90 degrees, and stitch each side, one side at a time (Figure 1A). On the other hand, the donor and recipient arteries rest naturally, and stitch together sequentially starting from the back side (back-wall technique), is a technique that requires skill; however, it does not require an assistant, and it is very useful when the blood vessel cannot be twisted (Figure 1B).
A

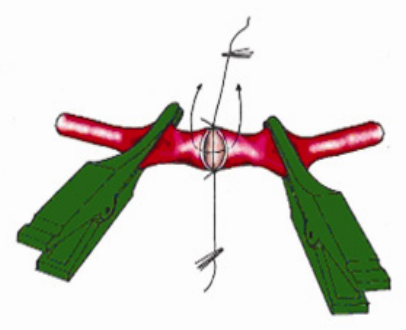

B

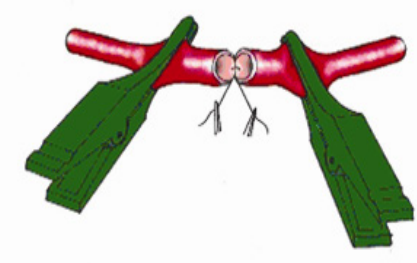

FIGURE 1 - Two methods of hepatic reconstruction in pediatric living donor liver transplantation. A: Twist type anastomosis. B: Non-twist type anastomosis.

Two types of training should be done for obtaining this type of anastomosis technique before animal training. First, nonliving material such as rubber globe should be used ${ }^{10}$. It has been more important to reduce the number of experimental animals from the 3 Rs point of animal welfare ${ }^{11}$. Recently, we focused on a simple training protocol through the usage of artificial blood vessels is introduced as follows. Briefly, cut off artificial blood vessel (Sunarrow Limited, Niigata, Japan), suture it with 8-0 or 9-0 suture and make knot under bench microscope, then press it by acrylic sheet to check the suture of the extravascular (Figure 2A) and intravascular side (Figure 2B). Technique is scored by the number of suture aiming 8 times in 20 minutes and the quality of suture such as the length of remnant suture and knot, equal length of each suture and interval between sutures. A result of this Handson training for young surgeons was summarized in Table 1. Faster the surgeons suture, high score they get. No relation was seen between the years of experience and the score. This training led to acquire the excellent technique and contribute to train surgeons with high level of technique. Ex vivo training using cryo-preserved animal artery is also useful as described previously ${ }^{12,13}$. Porcine materials have been used, while the cadaveric tissue has been considered to be useful ${ }^{14}$, but difficult to use for training in Japan ${ }^{15}$. 
A

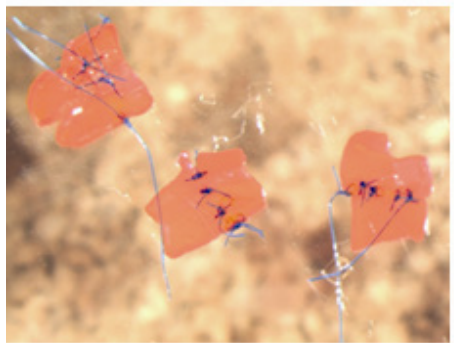

B

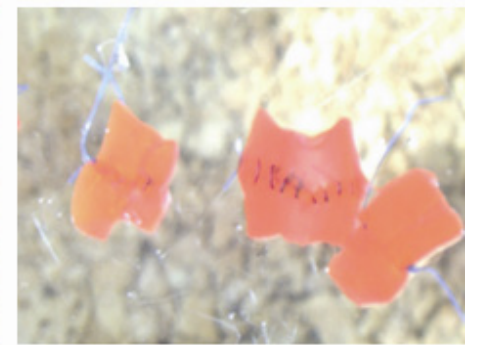

FIGURE 2 - Anastomosis training by using artificial blood vessels. A: Extravascular side. B: Intravascular side.

TABLE 1 - Results of training course. Values at the bottom of the table are expressed as means \pm standard deviation.

\begin{tabular}{ccccccc}
\hline No & Experience & $\begin{array}{c}\text { Total } \\
\text { score }\end{array}$ & $\begin{array}{c}\text { Evalua- } \\
\text { tion } \\
\text { Num- } \\
\text { ber of } \\
\text { Suture }\end{array}$ & $\begin{array}{c}\text { Extra- } \\
\text { vascu- } \\
\text { lar side }\end{array}$ & $\begin{array}{c}\text { Intra- } \\
\text { vascu- } \\
\text { lar side }\end{array}$ \\
\hline 1 & $\square$ & 4 & 2 & 2 & 0 & 0 \\
2 & & 5 & 8 & 6 & 1 & 1 \\
3 & & 5 & 11 & 7 & 2 & 2 \\
4 & & 6 & 5 & 5 & 0 & 0 \\
5 & & 6 & 13 & 8 & 3 & 2 \\
6 & & 7 & 2 & 2 & 0 & 0 \\
7 & & 7 & 8 & 5 & 2 & 1 \\
8 & & 8 & 9 & 5 & 2 & 2 \\
9 & 0 & 9 & 4 & 4 & 0 & 0 \\
10 & & 10 & 3 & 3 & 0 & 0 \\
11 & & 10 & 8 & 6 & 1 & 1 \\
12 & & 10 & 9 & 6 & 2 & 1 \\
13 & 0 & 10 & 13 & 8 & 2 & 3 \\
14 & & 11 & 6 & 4 & 1 & 1 \\
15 & 0 & 12 & 13 & 8 & 2 & 3 \\
$\square$ & & $8.0 \pm 2.5$ & $7.6 \pm 3.9$ & $5.3 \pm 2.0$ & $1.2 \pm 1.0$ & $1.1 \pm 1.1$ \\
\hline
\end{tabular}

Efficient experimental animal models are indispensable for the development of innovative medical technique and training ${ }^{7,16}$. The rat is a perfect animal for microsurgical training, because its physiology is well understood, and is large enough for reasonably easy surgical manipulation ${ }^{17,18}$. The rat abdominal aorta transection and re-anastomosis model is an extremely useful experimental microsurgical training technique ${ }^{17}$. Briefly, carry out laparotomy on anesthetized rats weighing about $250 \mathrm{~g}$, expose the artery on the leg-side of the left renal artery, and clamp above and below, leaving an interval of about $1 \mathrm{~cm}$ (Figure 3A). First, transection the artery at a right angle (Figure 3B), then suture the anterior wall with knotted sutures, twist 90 degrees, and do knotted sutures on the opposite side. After stitching the anterior surface with knotted sutures and pulling up the support thread for each side (Figure 3C), flip over and suture (Figure 3D).
A

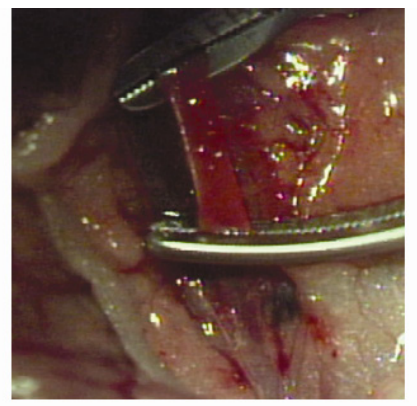

C

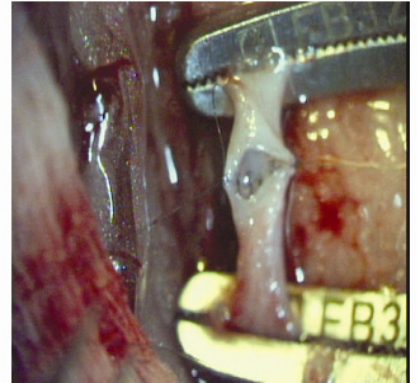



D

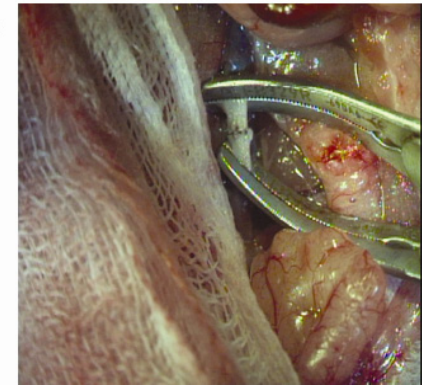

FIGURE 3 - A rat model of artery reconstruction. A: Clamping of abdominal aorta. B: Transectomy of the aorta. C: Twist type anastomosis. D: Final view (Just before declamping).

It is possible to see the technical level by sacrificing the rat about 7 days after this surgical procedure and observing the anastomosis area (Figure 4A). The experienced surgeons suture rapidly with equal length between the each interposed suture (Figure 4B). This training leads to development of both clinical and experimental skill.

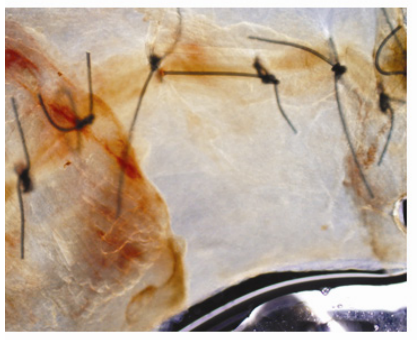

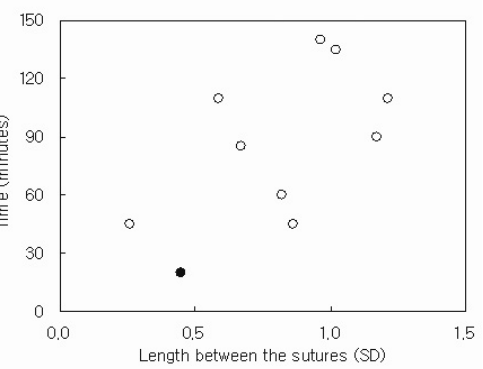

FIGURE 4 - Competency of the techniques after anastomosis in a rat model. A: Macroscopically finding of the site of anastomosis. B: Competency of the time required for complete anastomosis and standard deviation of the length between the each interposed suture. The solid and clear circles represent the experienced surgeon and beginners, respectively. 
Before performing this type of basic operation in the rat, practice until sufficiently skilled at suturing non-living materials and the like; only then should training with living animals be performed. Problems may occur with anastomosis, bleeding or stenosis ensues by using living animals. Therefore, the important point with this training is to carry it out being aware of clinical matters and adequate competency ${ }^{19,20}$.

\section{Technologies for beginners and intermediate}

\section{researchers}

Developments in organ transplantation over recent years would not have been possible without exploratory research of organ preservation solution and immunosuppressant. In exploratory research, since efficacy at the test tube level must be established in living animals, many standard rat models have been developed $^{21}$. The author has made this excellent technique more convenient, and has improved the rat organ transplantation model, so that many beginners and intermediate researchers can routinely use it.

Grafts have specific immunological characteristics, so it is necessary to actually transplant the organ using microsurgical technique. I briefly introduce some of the immunosuppressant for which exploratory research was performed using these animal models as the follows. The rat ectopic heart transplantation model is the most convenient and sensitive immunosuppressant screening system $^{22}$. Although hand suturing is often used for ectopic heart transplantation in the abdomen, there is also a convenient method of vascular anastomosis that uses a cuff for connecting blood vessels to polyethylene tubes and the like (Figure 5).

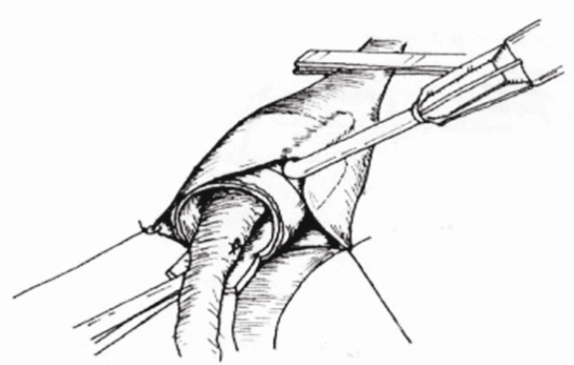

FIGURE 5 - Cuff technique for vascular anastomosis.

The ectopic heart transplantation model was used in order to clarify the chronopharmacology of deoxyspergualin ${ }^{23}$ and research of the new S1P agonist KRP203 was developed ${ }^{24}$. Since long ago, the rat orthotropic liver transplantation model has been used in research into specific immunological characteristics of the liver ${ }^{25}$. It has been widely used as the standard model since the 1980's. The success rate was improved even among beginners using this model $^{26}$. The key point when using a normal rat as the recipient is that, since intestinal tract stasis becomes stronger due to the portal vein clamp, it is necessary to speed up the anastomosis time; therefore, if a portal vein-superior vena cava shunt is put in place beforehand, it is possible to perform surgery stably ${ }^{27,28}$. By using this protocol, development and study of steroids used in liver transplantations was performed in the pharmaceutical sciences as well $^{29}$. In the rat small intestine transplantation model, in addition to the strong antigenicity of the small intestines rivaling that of the dermis, the graft versus host disease is also seen that is induced because of the lymphocytes contained in the small intestine. The world's first S1P agonist FTY720 which was developed in Japan was researched by using the rat small intestine transplantation mode $^{30}$. In this model also, vascular anastomosis was performed using the cuffs mentioned above. It was also possible to use the cuffs in the rat kidney transplantation model ${ }^{31,32}$. The cuff method can be applied for many different organ transplantations, but essentially it is a foreign body, and it is not suitable for long-term studies extending over several months. In long-term studies of immunosuppressant, study with anastomosis by manual stitching has come to be recommended ${ }^{33}$.

If appropriate experimental microsurgical training is accumulated, not only can beginners master it in several weeks, but, when one becomes accustomed to it, vascular anastomosis can be completed within a few minutes.

\section{Application for catheter-based technique in rats for}

\section{gene therapy}

The methods covered by the experimental microsurgical techniques are not limited to the field of vascular anastomosis for organ transplantations. A microscope can be used to enable passing a catheter through a blood vessel, allowing various drugs or gene vectors injection.

It is possible to broadly differentiate gene transfer into transfer using virus vector method and non-virus vector method. If the basic methods of experimental microsurgery are studied, it becomes possible to introduce thin catheters into the rat and mouse arteries. The author succeeded in using this technique from hepatic vein (Figure 6A) and with adeno-associated virus vectors to elicit kidney-specific gene expressionand. This type of technique also allows one to easily make an incision in the rat or mouse duodenum and insert the catheter in a retrograde fashion from the papilla, making it possible to efficiently introduce genes into the pancreatic exocrine tissues by using adeno-associated virus vectors (Figure 6B). 
A



$\mathrm{B}$

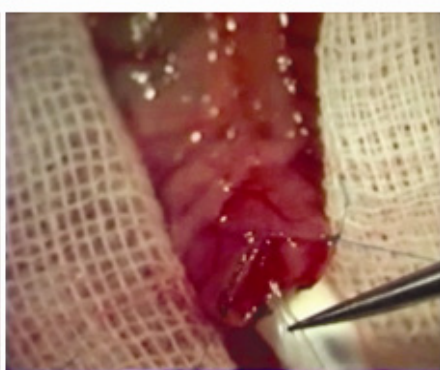

FIGURE 6 - Catheter technique. A: Catheter technique from hepatic vein. B: Injection through the papilla of the rat.

The hydrodynamic method, a non-virus vector method in which $\mathrm{DNA}^{34}$ or $\mathrm{RNA}^{35}$ is dissolved in a relatively large volume of solution and the genes are introduced to the organ or tissue through the vascular can also be performed using this catheter technique. Catheter technique can be used not only in medicine and pharmacology but also broadly in biological research.

\section{Conclusions}

Microsurgery is a key for clinical and experimental transplantation. I reviewed our training protocol to master microsurgical techniques and introduced several rat models. Mastering these techniques led us to easy perform various surgical techniques such as anastomsis, usage of cuff and catheter insertion. Microsurgery has the cross-disciplinary features of the sciences and skills for growth of Surgical Research.

\section{References}

1. Pratt GF, Rozen WM, Chubb D, Whitaker IS, Grinsell D, Ashton MW, Acosta R. Modern adjuncts and technologies in microsurgery: an historical and evidence-based review. Microsurgery. 2010 Nov;30(8):657-66. doi: 10.1002/micr.20809.

2. Nemeth N. Tribute to the "Father" of experimental microsurgery, Professor Sun Lee (1920-2015). Microsurgery. 2016 Feb;36(2):978. doi: $10.1002 /$ micr.30015.

3. Campisi C, Kirsch WM. Tribute to Professor Sun Lee-Experimental microsurgery pioneer. Ann Plast Surg. 2016 Feb;76(2):135-7. doi: 10.1097/SAP.0000000000000705.

4. Kobayashi E, Montero EF. A new concept of translational research in surgery. Acta Cir Bras. 2005 May-Jun;20(3):194. PMID: 16033176.

5. Nemeth N, Furka I, Miko I. Educational and research activity of the Department of Operative Techniques and Surgical Research, Institute of Surgery at the Medical and Health Science Center, University of Debrecen in Hungary. Acta Cir Bras. 2013 May;28(5):403-6. doi: 10.1590/S0102-86502013000500014.

6. Martins PN, Montero EF. Organization of a microsurgery laboratory. Acta Cir Bras. 2006 June;21(3):187-89. PMID: 16751934.

7. Balasundaram I, Aggarwal R, Darzi LA. Development of a training curriculum for microsurgery. Br J Oral Maxillofac Surg. 2010 Dec;48(8):598-606. doi: 10.1016/j.bjoms.2009.11.010.
8. Martins PN, Montero EF. Basic microsurgery training: comments and proposal. Acta Cir Bras. 2007 Feb;22 (1):79-81. PMID: 17293955.

9. Sanada Y, Wakiya T, Hishikawa S, Hirata Y, Yamada N, Okada N, Ihara Y, Urahashi T, Mizuta K, Kobayashi E. Risk factors and treatments for hepatic arterial complications in pediatric living donor liver transplantation. J Hepatobiliary Pancreat Sci. 2014 Jul;21(7):463-72. doi: 10.1002/jhbp.49.

10. Colebunders B, Matthew MK, Thomson JG. The use of a surgical glove in microsurgical training: a new point of view. Microsurgery. 2010 Sep;30(6):505-6. doi: 10.1002/micr.20785.

11. Akelina Y. Applying the " 3 Rs": Training Course in Surgical Techniques. Lab Animal. 2003;32(1):41-4. doi: 10.1038/ laban0103-41.

12. Olabe J, Roda J. Microsurgical cerebral aneurysm training porcine model. Neurol India. 2011 Jan-Feb;59(1):78-81. doi: 10.4103/00283886.76872 .

13. Abla AA, Uschold T, Preul MC, Zabramski JM. Comparative use of turkey and chicken wing brachial artery models for microvascular anastomosis training. J Neurosurg. 2011 Dec;115 (6):1231-5. doi: 10.3171/2011.7.JNS102013.

14. Atallah SB, Albert MR, deBeche-Adams TH, Larach SW. Robotic TransAnal Minimally Invasive Surgery in a cadaveric model. Tech Coloproctol. 2011 Dec;15(4):461-4. doi: 10.1007/s10151-0110762-9.

15. Kobayashi E. Present and aspects for cadaver surgical training in Japan. Kyobu Geka. 2015 Mar;68(3):204-11. PMID: 25743555.

16. Kotby MN, Wahba HA, Kamal E, El-Makhzangy AM, Bahaa N. Animal model for training and improvement of the surgical skills in endolaryngeal microsurgery. J Voice. 2012 May;26(3):351-7. doi: 10.1016/j.jvoice.2011.04.002.

17. Iwai S, Endo K, Kobayashi E. Training protocol for feline renal transplantation, using rat vascular anastomosis. Microsurgery. 2006;26(1):8-12. doi: 10.1002/micr.20202.

18. Sakrak T, Köse AA, Karabağli Y, Koçman AE, Ozbayoğlu AC, Cetịn C. Rat tail revascularization model for advanced microsurgery training and research. J Reconstr Microsurg. 2011 Sep;27(7):391-6. doi: 10.1055/s-0031-1281519.

19. Satterwhite T, Son J, Carey J, Zeidler K, Bari S, Gurtner G, Chang $\mathrm{J}$, Lee GK. Microsurgery education in residency training: validating an online curriculum. Ann Plast Surg. 2012 Apr;68(4):410-4. doi: 10.1097/SAP.0b013e31823b6a1a.

20. Price J, Naik V, Boodhwani M, Brandys T, Hendry P, Lam BK. A randomized evaluation of simulation training on performance of vascular anastomosis on a high-fidelity in vivo model: the role of deliberate practice. J Thorac Cardiovasc Surg. 2011 Sep;142(3):496503. doi: 10.1016/j.jtcvs.2011.05.015.

21. Kobayashi E, Kamada N, Enosawa S, Toyama N, Miyata M. Syngeneic small-bowel grafting increases susceptibility to lethal graft-versus-host disease in the rat. Eur Surg Res. 1995;27(1):1926. doi: $10.1159 / 000129368$.

22. Xiu D, Uchida H, Sugimoto K, Kasahara K, Nagai H, Fujimura A, Kobayashi E. Simplified method of heterotopic rat heart transplantation using the cuff technique: application to sublethal dose protocol of methotrexate on allograft survival. Microsurgery. 2001;21(1):16-21. PMID: 11426636.

23. Uchida H, Kobayashi E, Matsuda K, Mizuta K, Sugimoto K, Kawarasaki H, Hashizume K, Fujimura A. Chronopharmacology for deoxyspergualin: toxicity and efficacy in the rat. Transplantation. 1999 May;67(9):1269-74. PMID: 10342320.

24. Shimizu H, Takahashi M, Kaneko T, Murakami T, Hakamata Y, Kudou S, Kishi T, Fukuchi K, Iwanami S, Kuriyama K, Yasue T, Enosawa S, Matsumoto K, Takeyoshi I, Morishita Y, Kobayashi E. KRP-203, a noevl synthetic immunosuppressant, prolongs 
graft survival and attenuates chronic rejection in rat shin and heart allografts. Circulation. 2005;111 (2):222-9. doi: 10.1161/01. CIR.0000152101.41037.AB.

25. Kamada N, Davies HS, Roser B. Reversal of transplantation immunity by liver grafting. Nature. 1981 Aug;292:840-2. doi: $10.1038 / 292840 \mathrm{a} 0$.

26. Kobayashi E, Kamada N, Goto S, Miyata M. Protocol for the technique of orthotopic liver transplantation in the rat. Microsurgery. 1993;14(8):541-6. doi: 10.1002/micr.1920140812.

27. Delriviere L, Kamada N, Kobayashi E, Enosawa S, Goto S. Portosystemic shunt for orthotopic liver transplantation in the rat. J Surg Res. 1994 May;56(5):457-60. PMID: 8170147.

28. Klarik Z, Toth E, Kiss F, Miko I, Furka I, Nemeth N. A modified microsurgical model for end-to-side selective portacaval shunt in the rat. Intraoperative microcirculatory investigations. Acta Cir Bras. 2013 Sep;28(9):625-31. PMID: 24000054.

29. Chimalakonda AP, Montgomery DL, WeidanzJA, Shaik IH, Nguyen JH, Lemasters JJ, Kobayashi E, Mehvar R. Attenuation of acute rejection in a rat liver transplantation model by a liver-targeted dextran prodrug of methylprednisolone. Transplantation. 2006 Mar;81(5):678-85. doi: 10.1097/01.tp.0000177654.48112.b6.

30. Mitsusada M, Suzuki S, Kobayashi E, Enosawa S, Kakefuda T, Miyata M. Prevention of graft rejection and graft-versus-host reaction by a novel immunosuppressant, FTY720, in rat small bowel transplantation. Transpl Int. 1997 Sep;10(5):343-9. doi: 10.1111/ j.1432-2277.1997.tb00927.x.

31. Kamada N. A description of cuff techniques for renal transplantation in the rat: use in studies of tolerance induction during combined liver grafting. Transplantation. 1985;39(1):93-5. PMID: 3880972.

32. Martins PNA, Filatenkov A. Microsurgical techniques for experimental kidney transplantation and general guidelines to establish studies about transplantation immunology. Acta Cir Bras. 2003 Aug; 18(4):355-80.

33. Fujishiro J, Kudou S, Iwai S, Takahashi M, Hakamata Y, Kinoshita $\mathrm{M}$, Iwanami S, Izawa $\mathrm{S}$, Yasue $\mathrm{T}$, Hashizume $\mathrm{K}$, Murakami $\mathrm{T}$, Kobayashi E. Use of sphingosine-1- phosphate 1 receptor agonist, KRP-203, in combination with a subtherapeutic dose of cyclosporine A for rat renal transplantation. Transplantation. 2006 Sep;82(6):804 12. doi: 10.1097/01.tp.0000232687.78242. cd.
34. Inoue S, Hakamata Y, Kaneko T, Kobayashi E. Gene therapy for organ grafts using rapid injection of naked DNA: application to the rat liver. Transplantation. 2004 Apr;77(7):997-1003. doi: 10.1097/01.TP.0000118404.66106.E8.

35. Sato Y, Ajiki T, Inoue S, Fujishiro J, Yoshino H, Igarashi Y, Hakamata Y, Kaneko T, Murakamid T, Kobayashi E. Gene silencing in rat-liver and limb grafts by rapid injection of small interference RNA. Transplantation. 2005 Jan;79(2):240-3 doi: 10.1097/01. TP.0000147786.52502.2F.

\section{Acknowledgement}

To all staffs contributing to this project at Jichi Medical University and Keio University School of Medicine.

\section{Correspondence:}

Eiji Kobayashi

Department of Organ Fabrication, Keio University School of Medicine 35 Shinanomachi, Shinjuku, Tokyo 1608582, Japan

Phone: $+81-3-3353-1211$ ext 63968

FAX: +81-3-5315-4089

organfabri@a2.keio.jp

Received: Nov 21, 2015

Review: Jan 20, 2016

Accepted: Feb 19, 2016

Conflict of interest: none

Financial source: Sunarrow Limited

${ }^{1}$ Research performed to Department of Organ Fabrication, Keio University School of Medicine, Tokyo, Japan. 